\title{
EL “ESPÍRITU NUEVO" DE JOANOT MARTORELL: LAS LECTURAS DE DÁMASO ALONSO Y MARIO VARGAS LLOSA
}

En el primer volumen de la «Revista valenciana de filología), publicado en 1951, apareció un artículo de indudable interés para trazar la historia de la difusión de la novela de Joanot Martorell por tierras hispánicas: me refiero a "Tirant lo Blanc, novela moderna", de Dámaso Alonso. ${ }^{1}$ Esta monografia tiene su punto de partida en las ediciones que Martín de Riquer había preparado pocos años antes del original catalán y de la traducción castellana de 1511, que facilitaron la lectura y la investigación de la obra de manera muy significativa al fijar los textos y al ofrecer introducciones y notas que no solo constituían excelentes "estados de la cuestión", sino que también brindaban innumerables aportaciones y sugerencias que propiciaron el nacimiento de buena parte de la crítica tirantiana posterior. ${ }^{2}$ El propio Riquer, en su reciente Aproximació al "Tirant lo Blanc", al hablar de los comentarios que, a partir del Quijote, ha suscitado la obra, llama la atención sobre este breve ensayo, que considera "el primer gran estudi" de que disponemos, y recoge sus principales aportaciones estéticas y literarias. ${ }^{3}$

El interés de este trabajo reside, en primer lugar, en el relieve de su autor, quien, a partir de 1927, cuando ganó el Premio Nacional de Literatura por su ensayo Góngora y la literatura contemporánea, estaba llamado a convertirse en uno de los investigadores más sólidos e influyentes de la época (por no mencionar su quehacer poético, que en 1944 había culminado con Hijos de la ira): en 1939 ocupa la cátedra de Menéndez Pidal en la Universidad de Madrid, en 1948 ingresa en la Real Academia de la Lengua y en 1949 es nombrado director de la «Revista de Filología Española». Era ya por entonces, en definitiva, uno de los más señeros exponentes de la "Escuela Española de Filología" que constituyera don Ramón en el Centro de Estudios Históricos madrileño, como ha señalado Francisco Abad. ${ }^{4}$

1 Este artículo ocupaba las páginas 179-215, y se puede consultar también en el volumen octavo de sus Obras completas (Madrid, Gredos, 1985, págs. 499-536), aunque ya fue recogido en Primavera temprana de la literatura europea (Madrid, Guadarrama, 1960, págs. 201-253).

2 Ambas ediciones aparecieron en Barcelona: la primera publicada por Selecta, 1947 ("Biblioteca Perenne"), y la segunda, en tres volúmenes, por la Asociación de Bibliófilos, 1947-1949.

3 Barcelona, Quaderns Crema, 1990, págs. 22-24.

4 “La obra de Dámaso Alonso se destaca señera entre las muy importantes de todos sus colegas de escuela, y ello tanto por la continuidad y amplitud de la misma como por sus logros únicos; don Dámaso ha poseído lo mismo clarividencia en las cuestiones de fonética histórica, que sensibilidad para apreciar los hechos estéticos y 
No conviene olvidar tampoco que el relieve que adquiere Tirant en este trabajo debe ser contemplado desde los presupuestos estéticos que Alonso defendería en sus estudios sobre la novela española, factor que, unido a su entusiasmo como lector, perduraría muchos años en el recuerdo. Por ejemplo, meses antes de su muerte (acaecida el 25 de enero de 1990), se expresaba en los siguientes términos durante el curso de una entrevista:

- ¿Hay algún libro en la historia de la literatura que se apresuraría a firmar?

- ¡Muchos!

- Dígame alguno...

- La Celestina, El Quijote, El libro de Buen Amor, Tirant lo Blanch... Tantos que no acabaríamos.

- ¿Por qué Tirant? Se lo pregunto porque ya sabe que soy valenciana...

- Porque es la mejor novela que se escribió durante el siglo XV en Europa, y porque no hay duda de que excitó la imaginación de Cervantes. Yo escribí, allá por el año cincuenta y uno, un trabajo que se llamaba "Tirant lo Blanch, novela moderna", que publicó la «Revista de Filología Valenciana»(sic). Es una novela totalmente actual, por sus descripciones, las situaciones que narra, la libertad con que sus personajes se mueven... Sus diálogos son breves, rápidos, desenfadados, como si la hubieran escrito en el siglo XIX. Hay también una despreocupación moral absoluta, sólo se propone divertir, y lo curioso es que la Iglesia no la prohibió jamás.

- Ha dicho que Cervantes la leyó...

- Por supuesto, y admiraba mucho a su autor, el valenciano Joanot Martorell, y aprendió de él una buena lección. Pero lo que en El Quijote está en lucha, en conflicto, en Tirant convive sin contradicción, con armonía... Aunque la lección que te he dicho que Cervantes aprendió es mucho más amplia que la dualidad idealismo-materialismo, una lección general: de hombre a hombre, de novelista a novelista, de técnica a técnica.

- El que quisiera aprender catalán, ¿tiene alguna relación con su estudio sobre Tirant?

- En parte sí, porque yo estuve trabajando en la novela con la ayuda de Martín de Riquer, a quien le consulté muchas dudas. Pero a mí siempre me ha gustado el catalán por su sonoridad: yo estuve un año entero en la Universidad Autónoma de Barcelona, allá por el año 34, y lo entendía muy bien, lo que ocurre es que me hubiera gustado estudiarlo a fondo. 5

¿Cuáles son los factores que Dámaso Alonso destaca en la novela? Como Menéndez Pelayo, considera que Tirant lo Blanch se caracteriza por su "fragmentarismo positivo" y su "humor escéptico" y que "Martorell, burlón, sensual, minucioso, logicista, científico, si bien representa de lleno el fragmentado espíritu burgués, admite aún las formas exteriores de la fe unitaria caballeresca" (pág. 182). Este rasgo cardinal se observa en el papel de

capacidad analítica de los recursos estilísticos. El nombre de Dámaso Alonso es uno de los más egregios en la historia de los estudios filológicos en España" (en: "Dámaso Alonso y la Escuela Española de Filología", «Anthropos», 106-107/1990, pág. 82).

5 María Asunción Mateo, Retrato de Dámaso Alonso, Barcelona, Círculo de Lectores, 1990, págs. 62-63. 
"ingenioso, apto, técnico estratega" del héroe protagonista y en la "pedagogía" y el "positivismo científico" del autor, evidentes, según Alonso, en las variadas estrategias militares que van desgranándose a lo largo de la obra o en las explicaciones racionales dadas a los elementos mágicos. Pero, además, considera fundamental la “atmósfera” que respira el relato, con la cual, más allá de la verosimilitud boccacciana, "se nos comunica una especial manera de intuir la realidad" que deriva de "una nueva técnica en el narrar" (págs. 190-191), caracterizada porque tanto las circunstancias esenciales para el desarrollo de las acciones como las más nimias se entrelazan "con absoluta limpidez, cohesión y racionalidad” (pág. 192), se adopta una lengua cotidiana, de forma que la manera de hablar parece "rápida, desenfadada y naturalísima" (pág. 195), e, incluso, propicia situaciones de gran comicidad: "Asombra en este arte la libertad de movimientos, el placer en la descripción con pincelada rápida de actitudes, espacios, acciones, la reproducción de la palabra hablada en breves frases del más natural lenguaje diario" (pág. 198).

Se trataría, por consiguiente, de un tipo de realismo "vitalista", $\tan$ alejado del realismo "típico" de otros autores medievales (por ejemplo, Chaucer), como del "psicológico" de la Celestina; tan distante de la "seriedad" de Curial e Güelfa como de los arquetipos propios de la novela sentimental y caballeresca, que gozarían de una envidiable difusión a lo largo del siglo XVI. La razón que, en opinión de Dámaso Alonso, explicaría el escaso eco obtenido no sería otra que "no era un verdadero libro de caballerías" (pág. 200), sino un texto desmarcado de su tiempo, despreocupado moralmente - aunque defensor del cristianismo-, que se mueve entre el placer y el ideal. Y esto será así porque a lo largo de la novela "confluyen" técnicas medievales y modernas que entrelazan la "fe unitaria formalista" con la "fragmentación positiva y humorística de los tiempos nuevos" (pág. 214). Los comentarios últimos no pueden ser más relevadores: "Pero yo no sé por qué a este Joanot Martorell no lo veo lejano, al fondo de la oscuridad medieval. Le veo muy próximo, contemporáneo: un contemporáneo. Tiene ese gesto cansado, desilusionado, sólo incansable en la sensualidad, triste y al par burlón, del europeo de nuestros días".

Como apuntaba arriba, el valor de "Tirant lo Blanc, novela moderna", procede no sólo de los magistrales análisis desarrollados para la comprensión de la obra de Martorell, sino, además, de los referentes aportados para la comprensión del concepto de realismo, tan apreciado por Dámaso Alonso y la Escuela Española de Filología. Se comprendería, entonces, la afirmación según la cual "Tirant se salta toda la novela sentimental y la caballeresca para darse la mano con la novela realista española, es decir, con la que recibirá, imitará y continuará la Europa moderna" (pág. 202). Sin embargo, cabe observar que con el paso del tiempo, Alonso modificó su entusiasmo inicial por el texto valenciano. Así, en su artículo titulado "Enlace del realismo" (donde reivindica una "tradición española ininterrumpida" desde el Poema del Cid que, merced al Lazarillo, se entroncaría con la narración novelesca) apunta que "El lector moderno de un Amadis o de un Primaleón o aun de un Tirant lo Blanch (aunque más humano), sabe que nada más alejado del impulso de su corazón y de la demanda de la fantasía, que estos libros". 6 Esta matización se extiende cuando, en otro trabajo, al analizar el realismo medieval bajo la luz de Celestina, se de-

En: Obras completas, VII: Comentarios de Textos, Madrid, Gredos, 1985, pág. 484. 
tiene brevemente en nuestra obra: "Uno de los méritos del Tirant lo Blanc es que, por primera vez en la literatura peninsular, nos encontramos allí una abundancia de seres individuales que ya recordaremos siempre como únicos. [...] En Tirant la vida estaba reproducida como una embriaguez de vinos ligeros y deseos primaverales, como un friso de colores gayos y lleno de movimiento, pero falto de la tercera dimensión. El tono es de comedia: lo ligero basta. Son caracteres bien delimitados, pero no tienen profundidad."7

En cualquier caso, parece demostrado el interés de Dámaso Alonso por la novela de Martorell, que ya ha cumplido el quinto centenario de su publicación. En una época no tan lejana como aquella de los primeros cincuenta, este artículo despertó pocas curiosidades inmediatas, lo que explicaría, en parte, las escasas referencias en la crítica tirantiana posterior - aunque creo que se trata de un estudio más utilizado de lo que demuestran las referencias explícitas-, pero sirvió como llamada de atención de primer orden, que no conviene desdeñar, como, además de Martín de Riquer, observa siempre Mario Vargas Llosa.

Porque, en efecto, ha sido el escritor peruano una de las figuras que desde fechas más tempranas — cuando el género caballeresco era denostado por la crítica 0 , mucho peor, olvidado - emprendiera asedios más exitosos y reivindicaron con fortuna la modernidad del texto de Martorell. Mario Vargas Llosa ha manifestado en numerosas ocasiones que fue un "espíritu de contradicción" el que le condujo durante sus años universitarios en Lima hacia la biblioteca para comprobar si aquellos libros que su profesor de literatura del Siglo de Oro despachaba una argumentación condenatoria podían ser realmente tan fieros como los pintaban. Sería entonces cuando leería por vez primera el Tirant, también en este caso a partir de la edición de Riquer, despertando su más vivo entusiasmo. ${ }^{8} \mathrm{Ya}$ en España, reanudó su contacto con los textos caballerescos medievales y renacentistas en circunstancias que muchos han padecido sobradamente: "El helado caserón de la Biblioteca Nacional de Madrid tenía una magnífica colección y, resfríos aparte, pasé muchas tardes memorables allí, sumido en las aventuras laberínticas de Amadises, Esplandianes, Lisuartes, Palmerines y demás caballeros andantes".?

Fue a partir de esta gratificante experiencia que el autor de La ciudad y los perros intenta que la obra conozca la difusión popular que, a su juicio, merece, tal como nos recuerda en el proemio de su Carta de batalla por Tirant lo Blanc: "Me llena de vanidad

7 Ibid., pág. 565.

8 “Mi espíritu de contradicción me precipitó a la biblioteca a comprobar por mí mismo si aquellas novelas eran tan horribles como mi profesor las pintaba y para mi buena estrella la casualidad, disfrazada de bibliotecaria, puso en mis manos el Tirant lo Blanc, en la admirable edición crítica de 1947 de Martín de Riquer", en "Tirant lo Blanc: las palabras como hechos", conferencia pronunciada en el simposio internacional celebrado en la Real Academia de Buenas Letras de Barcelona, en noviembre de 1990, y ahora editado en su Carta de batalla por Tirant lo Blanc, Barcelona, Seix Barral, 1991, pág. 87. Parte de las ideas que expongo a continuación fueron expuestas en mi artículo "Carta de batalla de Mario Vargas Llosa", "Quimera» 110/1992, págs. 56-59.

9 "El último de los caballeros", «Quimera» 56/1989, pág. 12, reseña del ensayo de Edwin Williamson, The HalfWay House of Fiction. Don Quixote and Arthurian Romance, Oxford, Clarendon Press, 1984, incorporada como prólogo a la traducción española (Madrid, Taurus, 1991). 
haber vencido las reticencias de Carlos Barral a leer el libro, primero, y, luego, a hacer en Seix Barral una edición comercial de la novela. Se hizo en 1969, en dos volúmenes de la 'Biblioteca Breve de Bolsillo', preparada y prologada por Martí de Riquer. Que se agotara en pocos meses fue una rotunda demostración de algo que siempre sostuve: que, pese a sus larguras y a lo intrincado de su prosa, Tirant lo Blanc podía ser leída y gozada en su lengua original por cualquier hispanohablante someramente culto". ${ }^{10}$ Pero su influencia también sería determinante en la publicación de la traducción de J. F. Vidal Jové que Jaime Salinas editó ese mismo año en Alianza y que incorpora una introducción entusiasta que ahora pođemos disfrutar nuevamente. ${ }^{11}$ iCuáles eran las razones del interés de Vargas Llosa hacia esta obra? Pues que "Martorell es el primero de esa estirpe de suplantadores de Dios - Fielding, Balzac, Dickens, Flaubert, Tolstói, Joyce, Faulkner- que pretenden crear en sus novelas una realidad total, el más remoto caso de novelista todopoderoso, desinteresado, omnisciente y ubicuo" (pág. 11). Desde esta perspectiva comprendemos que Tirant lo Blanc pueda ser analizada como una novela histórica y militar, pero también costumbrista, erótica o psicológica, una "creación desinteresada", una "realidad distinta" cuyas estrategias narrativas alcanzan sus logros como consecuencia de que la materia empleada "adquiere autonomía, representatividad y poder de persuasión suficientes para vivir por cuenta propia, cuando ha sido organizada del único modo posible para que brotara en ella la vida" (pág. 58).

Sin embargo no se nos debe escapar el hecho de que buena parte de la crítica literaria de Vargas Llosa consagrada al análisis de autores que, por una razón u otra, han despertado su curiosidad se puede entender como un intento de explicar su propia obra, en ocasiones manifestado de forma indirecta. Así en el prólogo a su ensayo consagrado a Gustave Flaubert, recuerda que el primer capítulo "es un mano a mano entre Emma Bovary y yo en el que, por supuesto, hablo más de mí que de ella".12 Por esta razón no nos sorprende encontrar pasajes en los que expresa "la felicidad con que cualquier admirador del Amadís de Gaula y del Tirant lo Blanc descubre que alguna vez Flaubert escribió: 'Tu sais que c'est un des mes vieux rêves que d'écrire un roman de chevalerie $[\ldots]^{\prime} "{ }^{13}$

Y es que la ambición narrativa del Tirant y de la narrativa caballeresca aparece como tema recurrente en el ideario que nuestro autor aplica a sus textos literarios predilectos, ya sea Madame Bovary, como hemos visto, o, también por ejemplo, Cien años de soledad, como subyace en el estudio titulado García Márquez: historia de un deicidio. ${ }^{14}$ Según Alexander Coleman, esta "historia de la ficción como una restitución laica del logos re-

10 Carta de batalla por Tirant lo Blanc, ob. cit., pág. 5 .

11 Prólogo a Joanot Martorell y Martí Joan de Galba, Tirant lo Blanc. Madrid, Alianza, 1969, recogido en Carta de batalla por Tirant lo Blanc, ob. cit., págs. 9-58.

12 La orgia perpetua. Flauberty "Madame Bovary", Barcelona, Seix Barral, 1975, pág. 12.

13 Ibid., pág. 53.

14 Caracas, Monte Ávila, 1971. 
cientemente desacralizado es uno de los más importantes hilos comunicantes entre autores aparentemente tan diferentes como Martorell, Flaubert y García Márquez".15

Desde esta perspectiva la lectura del segundo artículo que se recoge en la Carta de batalla por Tirant lo Blanc, "Martorell y el elemento añadido" (originariamente una conferencia pronunciada en 1970 que, con posterioridad, fue utilizada como estudio preliminar a la edición de Riquer de las cartas de batalla de Joanot Martorell) ${ }^{16}$, introduce un nuevo matiz de indudable interés para encuadrar la teoría narrativa de Vargas Llosa: "Como todo gran creador, Joanot Martorell edificó su novela a imagen y semejanza de la realidad de su época, utilizando todos los materiales que su tiempo le ofrecía" (pág. 85). Así el concepto de la autonomía de la obra de arte se ve asociado al de realismo, produciendo un resultado final que no posee un objetivo documentalista - por calificarlo de alguna manera - sino que trasciende los límites literarios, pues "Martorell al mismo tiempo que expresó, rectificó su realidad: al mismo tiempo que dijo la vida, la contradijo".

Pero, ¿cómo se refleja esta teoría en la obra novelística del escritor peruano? Tal vez esta pregunta haya obtenido una respuesta entre aquellos lectores de textos tan diferentes como Los cachorros, La casa verde, Conversación en La Catedral o La guerra del fin del mundo, pues, en efecto, si cambiamos muchas de las alusiones a Martorell y en su lugar utilizamos el nombre de nuestro autor, podríamos obtener un (auto)análisis tan sencillo como de incalculable valor. De ahí la eficacia de manejar la imagen de una "teoría de los espejos".

Parece más arriesgado intentar un estudio de influencias directas, aunque siempre resulte más atractivo. De entre los pocos que se han acometido, merece especial atención el firmado por Frank Dauster: "Pantaleón y Tirant: puntos de contacto". ${ }^{17}$ Este investigador intenta demostrar que Pantaleón y las visitadoras (1973), una de las más célebres y polémicas novelas de nuestro autor por su temática (el servicio organizado de prostitutas para desfogar al ejército), se construye como la contraimagen irónica de la novela medieval. Redactada en los mismos años que los dos estudios tirantianos citados, estaría, según Dauster, "más cerca de Tirant de lo que están las novelas anteriores de Vargas Llosa", tanto por ofrecernos una contraimagen irónica del protagonista, como por su temática erótico-militar, su sentido del humor y el formalismo léxico de algunos de sus pasajes: "en su irónico retrato de 'un gentil caballero tan imperfecto", Vargas Llosa está diciéndo-

15 "La transfiguración de la novela de caballería" en: José Miguel Oviedo (ed.), Mario Vargas Llosa, Madrid, Taurus, 1981, pág. 271. Más adelante afirma que "otro secreto hilo unificador en su crítica, otra clave de su visión singular de la imaginación en relación con la realidad es el sentido especial que da a la palabra rito" (pág. 272).

16 El combate imaginario, Barcelona, Barral, 1972 (reeditado por Sirmio en 1990).

17 Publicado en «Hispanic Review» 48/1980, págs. 269-285, y traducido en la compilación ya citada de J. M. Oviedo, págs. 237-251. 
nos que Pantaleón, a diferencia de su modelo, es incapaz de ser más que mediocre porque finalmente todos los códigos han sido traicionados". ${ }^{18}$

El tercer texto de la Carta de batalla... fue la conferencia que Vargas Llosa leyó en la Real Academia de Buenas Letras de Barcelona sobre el Tirant lo Blanc en noviembre de 1990, es decir, que ha sido redactada veinte años más tarde que los dos ensayos anteriores. A lo largo de sus páginas, nos reencontramos con los temas más queridos del autor, como el recuerdo de su primera lectura, su carácter modélico o su ambición totalizadora, pero también su vindicación de una literatura de consumo masivo y calidad literaria, injustamente tratada por la crítica.

No obstante, conviene tener en cuenta un elemento novedoso en los comentarios de nuestro autor sobre el Tirant, que ya había sido esbozado con anterioridad pero que adquiere un notable protagonismo: "las palabras como hechos"; o lo que es igual, que las palabras son las protagonistas de la historia narrada, "son las palabras antes que las acciones o los caracteres o los paisajes las que constituyen la realidad básica de la ficción, el sustento del universo narrativo, esa atmósfera, sustancia y horizonte dentro de los cuales se van delineando los perfiles de los héroes, sus proezas y debilidades, la gracia de sus heroínas, la picardía de sus bufones y la ferocidad de sus matanzas" (pág. 98). Una afirmación que, teniendo en cuenta las relaciones señaladas entre creador y crítico, tal vez nos ofrezcan una buena pista de los intereses actuales y de los posibles resultados futuros de Vargas Llosa.

En cualquier caso, más allá de cualquier hipotética apuesta, resulta notorio el interés de las contribuciones de Dámaso Alonso y Mario Vargas Llosa en torno a la novela de Joanot Martorell, que, junto a las de Martín de Riquer (evidentemente en otro plano muy diferente), configuran un peculiar triunvirato de valedores que muy pocos textos medievales catalanes han gozado a lo largo de nuestro siglo. Y, recordemos, que como ha señalado el narrador peruano, "por estúpido que parezca, no puedo dejar de sentir que esta resurrección y apoteosis del Tirant lo Blanc es también una victoria mía, algo que de algún modo recompensa la fidelidad del más intransigente de sus valedores". 19

18 Ibid., pág. 251. Más recientemente, Leopoldo M. Bernucci ha vuelto a subrayar el interés de la comparación entre los estudios de novelas caballerescas y la narrativa del escritor peruano en un artículo titulado "La guerra del fin del mundo y la Edad Media actualizada", «Nueva Revista de Filologia Hispánica» 38/1990, págs. 359-377.

19 Carta de batalla por Tirant lo Blanc, ob. cit., pág. 7. 


\section{"NOVI DUH" JOANOTA MARTORELLA: \\ INTERPRETACIJI DÁMASA ALONSA IN MARIA VARGASA LLOSE}

Viteški roman katalonskega avtorja Joanota Martorella Tirant lo Blanc je vedno vzbujal veliko pozornosti literarne kritike. Mnogi so pisali o njem, med drugimi tudi trije tako odlični avtorji kot so Dámaso Alonso, Martín de Riquer in Mario Vargas Llosa, ki predstavljajo nekakšen triumvirat $\mathrm{v}$ vrednotenju Martorellovega romana $\mathrm{v}$ 20. stoletju.

Dámaso Alonso je leta 1951 objavil eno prvih poglobljenih študij z naslovom Tirant lo Blanc, moderni roman. Martín de Riquer, ki je tudi prevedel roman iz katalonščine v kastiljščino in ga opremil s komentarji, je srednjeveškemu delu posvetil precej svojih kritiških misli. Pisatelj Mario Vargas Llosa pa se je pri razlagi romana Tirant lo Blanc skušal poglobiti predvsem v lastno literarno delo in najti stične točke med svojo in Martorellovo estetiko. 